\title{
Ventilatory function and winter fresh fruit consumption in a random sample of British adults
}

\author{
David P Strachan, Brian D Cox, Sharon W Erzinclioglu, D Eurof Walters, \\ Margaret J Whichelow
}

\begin{abstract}
The relation between ventilatory function and the reported frequency of consumption of fresh fruit and fruit juice was studied among 1502 lifelong nonsmokers and 1357 current smokers aged 18-69 with no history of chronic respiratory disease. Forced expiratory volume in one second $\left(F E V_{1}\right)$ was assessed by turbine spirometry. As winter fruit consumption was more widely dispersed than summer consumption and few subjects ate fruit more frequently in the winter, winter fruit consumption was taken as an indicator of habitual (year round) consumption. After adjustment for sex, age, height, cigarette consumption, region of residence, and household socioeconomic group, FEV $_{1}$ was associated with winter fruit consumption. The mean adjusted $F_{1} V_{1}$ among those who never drank fresh fruit juice and ate fresh fruit less than once a week during the winter was $78 \mathrm{ml}$ lower $(95 \%$ confidence interval 24-132 $\mathrm{ml}$ ) than the mean for the other subjects. A similar difference was found in all age-sex groups and among both current smokers and lifelong non-smokers. Antioxidant and other actions of vitamin $\mathbf{C}$ may protect against pulmonary emphysema, or reduce bronchoconstrictor responses to environmental pollutants.
\end{abstract}

Cigarette smoking is a powerful determinant of morbidity and mortality from chronic obstructive airways disease, ${ }^{1}$ but several observations suggest that other factors may also be important. Mortality from chronic bronchitis and lung cancer shows different patterns over time and between geographical areas of England and Wales. ${ }^{2}$ The differentials in age standardised bronchitis mortality across occupational social classes in England and Wales are about twice as great as the equivalent differentials in mortality from lung cancer. ${ }^{3}$ Individual smokers show considerable variation in their rates of decline of ventilatory function, ${ }^{4}$ and it has been suggested that factors related to social class other than smoking may determine lung function among elderly men. ${ }^{5}$

Irreversible airflow obstruction related to respiratory bronchiolitis and pulmonary emphysema $^{1}$ is of greatest relevance to disability and death from chronic obstructive airways disease. ${ }^{467}$ The pathogenesis of pulmonary emphysema is thought to depend on an imbalance between proteolytic enzymes, which are released by neutrophils and macrophages on exposure to cigarette smoke, and antiproteases (particularly $\alpha_{1}$ antitrypsin), which are inactivated by oxidants in cigarette smoke and by superoxide anions released from alveolar macrophages. ${ }^{1}$ High tissue concentrations of antioxidants, such as vitamins $C$ and $\mathrm{E}$, may therefore offer some protection against destruction of the lung parenchyma by tobacco smoke. ${ }^{8}$ Vitamin $\mathrm{C}$ may also promote repair of such damage and influence lung growth and development through its effect on collagen synthesis. ${ }^{9}$ Most land mammals are capable of synthesising ascorbic acid, and have much higher tissue concentrations of the vitamin than man, ${ }^{10}$ which may explain why it has been difficult to produce an animal model for emphysema induced by tobacco smoke. ${ }^{1}$

Several studies have found concentrations of vitamin $C$ in the plasma or white blood cells to be about $30 \%$ lower in smokers than nonsmokers. ${ }^{11-15}$ British smokers of all ages consume less fresh fruit and vegetables ${ }^{14-16}$ and therefore less dietary vitamin $\mathrm{C}^{17}$ than nonsmokers. In addition, smokers appear to have a high metabolic turnover of ascorbic acid and require higher daily intakes to achieve blood concentrations similar to those of nonsmokers. ${ }^{18}$

In Britain consumption of fresh fruit and vegetables and dietary intake of vitamin $C$ show geographical and social variations that are the opposite of the trends in mortality from chronic obstructive airways disease. Fruit and vegetable consumption is greatest in rural areas, in the south and east of Britain, and among families with high incomes ${ }^{161920}$; and vitamin $\mathrm{C}$ intake is lowest among poor households and in urban areas of the north and west of Britain. ${ }^{19}$ Unusually low blood concentrations of ascorbic acid have been reported from a population survey of Scottish men, even among non-smokers. ${ }^{15}$

These "ecological" correlations are consistent with a protective effect of vitamin $C$ in chronic obstructive airways disease. Hitherto few studies have collected information about both respiratory diseases and dietary habits, though a link with alcohol has been suggested. ${ }^{21}$ An inverse association between bronchitis diagnosed by a physician and both dietary and plasma vitamin $\mathrm{C}$ concentrations among a representative sample of adults in the United States has recently been reported, which was independent of age and lifetime 
cigarette consumption. ${ }^{22}$ This paper uses data from a recent survey of British adults ${ }^{163}$ to explore the relation between fresh fruit intake and ventilatory function.

\section{Methods}

INTERVIEW

The health and lifestyle survey interviewed 9003 adults, a randomly selected sample of individuals aged 18 or over who were resident in England, Scotland, or Wales during 1984 and 1985. A general account of the methods of sample selection, data collection, and preliminary analyses have been published. ${ }^{16}$

The interviews were carried out in the respondents' homes and inquired about lifetime smoking habits. Lifelong non-smokers and current regular cigarette smokers (smoking one or more cigarettes a day) were distinguished from occasional smokers, ex-smokers and smokers of pipes or cigars only (grouped together as "other" smokers). Lifetime cigarette consumption was estimated for current regular smokers as the product of current consumption and years of smoking.

Additional information obtained at interview included current exposure to smoking by other household members, parental smoking behaviour, self assessed frequency of alcohol consumption, and questions about exercise at work and during leisure time. Each individual was assigned to a "household socioeconomic group" on the bais of the 1980 Registrar General's classification ${ }^{24}$ to code men and single or divorced women by their own present or past occupation, married women by their husband's occupation, and widows by their former husband's occupation.

\section{FOOD FREQUENCY QUESTIONNAIRE}

Dietary habits were assessed mainly by a food frequency questionnaire ${ }^{16}$ similar to that validated by comparison with weighted dietary records. ${ }^{25}$ Respondents were asked to rate their usual consumption of various foods on a six point scale: never, less than once a week, once or twice a week, most days, once a day, more than once a day. The food items included fresh fruit in summer, fresh fruit in winter, and pure fruit juice. Consumption of fresh fruit (on the six point scale used) had a more widely dispersed distribution in the winter than in the summer, so the former was used in the analysis.

Consumption of fruit juice and fresh fruit during the winter was analysed separately and in combination. A dichotomous variable was created to identify individuals who were likely to have a low vitamin $\mathrm{C}$ intake from these items. Subjects who denied ever drinking pure fruit juice and who ate fresh fruit less than once a week in the winter were considered to have a "low" fruit or juice intake, and those who ate fruit at least once a week during winter or drank fruit juice at all were grouped together as having a "high" fruit or juice intake.

The dose-response relationship across the whole range of winter fruit intake was assessed by comparing subjects with each of the six reported frequencies of consumption, irrespective of the amount of fruit juice consumed.

\section{VENTILATORY FUNCTION MEASUREMENTS}

After the interview participants who gave consent were visited at home by a trained research nurse, who performed simple physiological measurements. Standing height was measured with a portable stadiometer. Forced expiratory volume in one second $\left(\mathrm{FEV}_{1}\right)$ was measured with an electronic turbine spirometer (Micro Medical Instruments, Rochester), which had been validated previously. ${ }^{26}{ }^{27}$ Each spirometer was calibrated at the start of each wave of data collection and rechecked at the end by placing it in series with a Vitalograph spirometer. In the few instances in which significant calibration drift had occurred the intervening measurements were discarded.

After a period of instruction and a trial attempt, each subject was asked to perform three forced expiratory manoeuvres, and the maximum value of $\mathrm{FEV}_{1}$ recorded has been used in the analysis. Measurements were discarded if the subject had an acute respiratory infection, or if the nurse indicated that the completion of the expiratory manoeuvre was unsatisfactory. ${ }^{16}$

The measurements of $\mathrm{FEV}_{1}$ in this study correspond very closely to those obtained by Schoenberg et al. ${ }^{28}$ Comparison of the equivalent values for forced vital capacity, however, suggest a systematic underestimation in the health and lifestyle survey, probably because of the difficulties in determining the completion of the forced expiratory manoeuvre without a graphical presentation of the volumetime curve. The ratio of $\mathrm{FEV}_{1}$ to forced vital capacity therefore is not presented.

\section{EXCLUSIONS}

Analyses were limited to white subjects under 70 years of age because there were relatively few elderly people without a history of respiratory disease, especially among the smokers, in whom the expiratory manoeuvres were satisfactorily completed. Less than $5 \%$ of respondents were from non-white ethnic groups, and these were excluded from the analysis because the relation between age, height, and spirometric indices varies by ethnic group. ${ }^{28}$ Seven individuals who had been recommended a diet containing a lot of fruit and vegetables for medical reasons were also excluded.

Subjects with a self reported history of past or present asthma, bronchitis, or other chest problems were grouped together as having a history of "chronic respiratory disease." Insufficient data were collected in the survey to allow adequate distincton of current and past respiratory complaints. These subjects have therefore been excluded from the analyses of lung function, but their reported fruit or juice intake is presented for comparison with recent reports. ${ }^{22}$ Former smokers, occasional current smokers (of less than one cigarette a day), and smokers of pipe or cigars only have also been excluded from the analysis of $\mathrm{FEV}_{1}$ because of the difficulty of controlling adequately for smoking in the analysis of data on ventilatory function in this heterogeneous group.

The analyses of ventilatory function were thus confined to 1357 current cigarette smokers 
and 1502 lifelong non-smokers with no history of respiratory disease.

\section{STATISTICAL ANALYSIS}

Measurements of FEV , were adjusted for sex, age, and height by the use of polynomial regression equations constructed from the data for the lifelong non-smokers with no history of respiratory disease. Separate equations were fitted for each sex, with age (up to cubic terms) and height (up to quadratic terms) as the independent variables and $F E V_{1}$ as the dependent variable. Predicted values of $\mathrm{FEV}_{1}(\mathrm{ml})$ for all individuals in the study were then calculated from their height $(\mathrm{H})$ in $\mathrm{cm}$ and age $(\mathrm{A})$ in years by means of the following regression coefficients.

For men:

$2674.90-17 \cdot 0774 \mathrm{H}+0 \cdot 142912 \mathrm{H}^{2}$

$+7.46970 \mathrm{~A}-0.481479 \mathrm{~A}^{2}+0.0010792 \mathrm{~A}^{3}$

For women:

$-3901.56+55.0264 \mathrm{H}-0.095483 \mathrm{H}^{2}$

$+44.30424 \mathrm{~A}-1.263004 \mathrm{~A}^{2}+0.0069413 \mathrm{~A}^{3}$

The difference between the observed and the predicted $\mathrm{FEV}_{1}$ for each individual was used as the outcome variable for the analyses presented here. Similar conclusions were obtained from analyses using the ratio of observed to predicted values of $\mathrm{FEV}_{1}{ }^{29}$

The effect of low fruit or juice intake on ventilatory function and the dose-response relationship between winter fruit consumption and ventilatory function were investigated by fitting multiple regression models for lifelong non-smokers and current cigarette smokers, separately and in combination. These models included as explanatory variables pack years of smoking (separate intercept, linear, and quadratic terms for each sex), region of residence (nine English regions, Scotland, Wales), and six household socioeconomic groups (professional, employers and managers, other non-manual, skilled manual, semi skilled and personal service, unskilled manual). The independent effects of "low" or "high" fruit or juice intake and of different frequencies of winter fruit consumption were assessed by adding them to this core model. Winter fruit intake was modelled as a factor to generate adjusted mean $\mathrm{FEV}_{1}$ residuals for each frequency of consumption, or as a continuous variable to assess the significance of the linear trend in adjusted means across the six frequency categories (graded 1-6).

The effect of low fruit or juice intake was investigated further by fitting separate models for five age groups $(18-29,30-39,40-49,50-59$, 60-69) for each sex.

Further analyses among the lifelong nonsmokers with no history of respiratory disease included as additional explanatory variables urban-rural type of area (five categories), parental smoking (neither, mother, father, both), presence of a smoker in the household (yes, no), self assessed frequency of alcohol consumption (seven graded categories), amount of physical effort expended at work (four graded categories), average leisure time spent walking per week, participation in energetic leisure activities in the last fortnight, and participation with parents in energetic activities as a child.

\section{Results}

DISTRIBUTION OF LOW FRUIT OR JUICE INTAKE The patterns of fresh fruit consumption in the summer by sex, age, region, socioeconomic group, and smoking habit have been published. ${ }^{16}$ Similar trends were found for winter fruit consumption, which was more frequent among women, older subjects, non-smokers, respondents from the south east of Britain, and the non-manual socioeconomic groups. Table 1 shows the percentage of subjects with "low" fruit or juice intake by age, sex, smoking habit, household socioeconomic group, and history of chronic respiratory disease. When other factors were held constant, current smokers were more likely to have a low intake of fruit or fruit juice, but "other" smokers were similar to lifelong non-smokers. Within groups defined by smoking habit, subjects from non-manual classes were less likely to have a low fruit or juice intake. Within non-manual and manual socioeconomic groups the proportion with a low fruit or juice intake did not differ greatly between those with and those without a history of chronic respiratory disease.

Table 1 Percentage of subjects with "low" fruit/juice intake by sex, age, household socioeconomic group, smoking habit and history of respiratory disease (denominator populations in parentheses)

\begin{tabular}{|c|c|c|c|c|c|c|c|c|c|c|}
\hline \multirow[b]{3}{*}{ Age (y) } & \multicolumn{8}{|c|}{ No history of chronic respiratory disease } & \multirow{2}{*}{\multicolumn{2}{|c|}{$\begin{array}{l}\text { History of chronic } \\
\text { respiratory disease }\end{array}$}} \\
\hline & \multicolumn{2}{|c|}{ Lifelong non-smokers ${ }^{\star}$} & \multicolumn{2}{|c|}{ Current smokers ${ }^{\star}$} & \multicolumn{2}{|c|}{ "Other" smokers $\dagger$} & \multicolumn{2}{|l|}{ All subjects } & & \\
\hline & $\begin{array}{l}\text { Non-manual } \\
\%(n)\end{array}$ & $\begin{array}{l}\text { Manual } \\
\%(n)\end{array}$ & $\begin{array}{l}\text { Non-manual } \\
\%(n)\end{array}$ & $\begin{array}{l}\text { Manual } \\
\%(n)\end{array}$ & $\begin{array}{l}\text { Non-manual } \\
\%(n)\end{array}$ & $\begin{array}{l}\text { Manual } \\
\%(n)\end{array}$ & $\begin{array}{l}\text { Non-manual } \\
\%(n)\end{array}$ & $\begin{array}{l}\text { Manual } \\
\%(n)\end{array}$ & $\begin{array}{l}\text { Non-manual } \\
\%(n)\end{array}$ & $\begin{array}{l}\text { Manual } \\
\%(n)\end{array}$ \\
\hline \multicolumn{11}{|l|}{ Men } \\
\hline $18-29$ & $4(75)$ & $11(131)$ & $4(53)$ & $24(119)$ & $0(39)$ & $10(39)$ & $2(168)$ & $16(288)$ & $9(56)$ & $17(102)$ \\
\hline $30-49$ & $4(113)$ & $11(74)$ & $13(106)$ & $27(189)$ & $4(164)$ & $13(128)$ & $6(383)$ & $19(391)$ & $7(164)$ & $19(160)$ \\
\hline $50-69$ & $2(42)$ & $5(38)$ & $23(47)$ & $33(125)$ & $8(137)$ & $19(160)$ & $10(226)$ & $23(323)$ & $12(98)$ & $23(193)$ \\
\hline \multicolumn{11}{|l|}{ Women } \\
\hline $18-29$ & $3(150)$ & $13(123)$ & $6(80)$ & $23(123)$ & $0(40)$ & $15(47)$ & $4(270)$ & $17(293)$ & $1(71)$ & $13(89)$ \\
\hline $30-49$ & $3(256)$ & $4(212)$ & $8(139)$ & $18(198)$ & $2(140)$ & $6(119)$ & $4(535)$ & $10(529)$ & $6(167)$ & $12(206)$ \\
\hline $50-69$ & $7(152)$ & 9 (136) & $18(66)$ & $18(112)$ & $3(86)$ & $10(86)$ & $8(303)$ & $12(335)$ & $10(115)$ & $18(205)$ \\
\hline
\end{tabular}

* Groups included in the analyses shown in tables 2 and 3.

†Former regular cigarette smokers and current smokers of cigars only, pipe only, or less than one cigarette a day. 


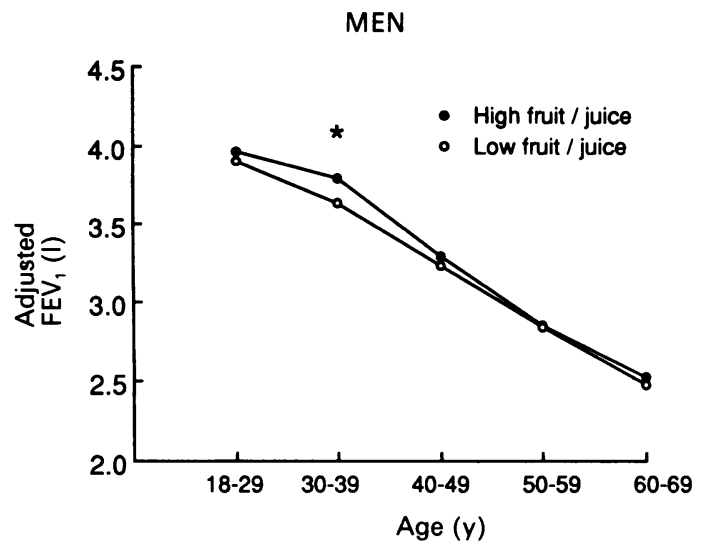

WOMEN

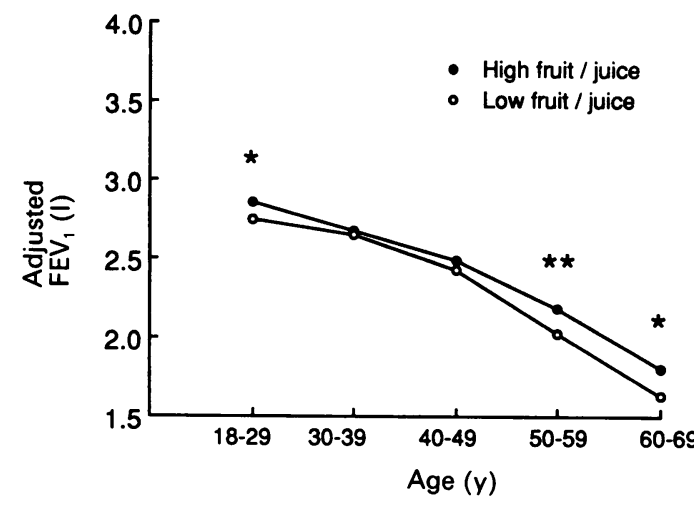

Adjusted $\dagger$ mean FEV (litres) by age group and consumption of fruit or juice ( $a$ ) men and ( $b$ ) women.

Data points

\begin{tabular}{llllll} 
& \multicolumn{4}{l}{ Consumption of fruit or juice } \\
\cline { 2 - 3 } & High & Low & & High & Low \\
\cline { 2 - 3 } \cline { 5 - 5 } Age (y) & Men & & & Women & \\
\hline $18-29$ & 3.968 & 3.899 & 2.855 & $2.741^{\star}$ \\
$30-39$ & 3.793 & $3.633^{\star}$ & 2.666 & 2.645 \\
$40-49$ & 3.295 & 3.230 & 2.485 & 2.421 \\
$50-59$ & 2.856 & 2.837 & 2.187 & $2.025^{\star \star}$ \\
$60-69$ & 2.519 & 2.481 & 1.802 & $1.633^{\star}$
\end{tabular}

†Adjusted within age groups for age, height, smoking habit, and household socioeconomic group. ${ }^{\star} p<0.05$; $\star \star \mathrm{p}<0.01$.
FEV, AND FRUIT OR JUICE INTAKE BY AGE AND SEX The figure shows the mean $\mathrm{FEV}_{1}$ by sex, 10 year age groups, and "low" or "high" fruit or juice intake, adjusted for age, height, socioeconomic group and smoking habit. Within each age-sex group, subjects with a "low" fruit or juice intake had a lower mean $\mathrm{FEV}_{1}$ than those with a "high" intake. These differences were significant at the $5 \%$ level in four of the five age groups. Both the absolute and the relative difference were greatest amongst older women.

When all age groups and the two sexes were combined, there was a highly significant difference in mean $\mathrm{FEV}_{1}$ residuals of $77.9 \mathrm{ml}$ (95\% confidence interval 23.9 to $131.9 \mathrm{ml}$, $t=2 \cdot 83, \mathrm{df}=2834, \mathrm{p}=0 \cdot 005)$ between those with low and high intakes of fruit or juice after adjustment for region, socioeconomic group, and lifetime cigarette consumption. Similar differences were observed for current smokers $(65.8 \mathrm{ml}, 95 \% \mathrm{CI}-1.7$ to $133.3 \mathrm{ml})$ and lifelong non-smokers $(85.2 \mathrm{ml}, 95 \% \mathrm{CI}$ -9.9 to $180.5 \mathrm{ml}$ ).

\section{TRENDS IN FEV 1 BY FREQUENCY OF FRESH FRUIT} CONSUMPTION

Table 2 shows the mean $\mathrm{FEV}_{1}$, for current smokers and lifelong non-smokers by reported frequency of fresh fruit consumption in winter. Overall, the trend of decreasing $\mathrm{FEV}_{1}$ with decreasing frequency of winter fruit consumption was significant $(p=0.03)$. A test of heterogeneity of slopes did not suggest a significant difference in the direction or magnitude of these trends among the lifelong non-smokers and current smokers $(t=0.41, \mathrm{df}=2832$, $\mathrm{p}=0.68)$. Among current smokers, however, there was little effect of fruit intake on ventilatory function at frequencies above once a week, whereas lifelong non-smokers who consumed fresh fruit more than once a day had particularly high values of adjusted $\mathrm{FEV}_{1}$. The gradient of decreasing $\mathrm{FEV}_{1}$ with decreasing frequency of winter fruit consumption remained significant for the lifelong nonsmokers $(p=0.04)$, but not for the current smokers $(\mathrm{p}=0.36)$.

Table 2 Adjusted ${ }^{\star}$ mean difference between observed and predicted FEV, by frequency of winter fruit consumption among current smokers and lifelong non-smokers with no history of respiratory disease (number of subjects in parenthesest)

\begin{tabular}{llcc}
\hline & \multicolumn{2}{l}{ Observed - predicted FEV,$(\mathrm{ml})$} \\
\cline { 2 - 4 } $\begin{array}{l}\text { Frequency of fresh fruit } \\
\text { consumption in winter }\end{array}$ & Current cigarette smokers & Lifelong non-smokers & $\begin{array}{c}\text { Current smokers and } \\
\text { lifelong non-smokers }\end{array}$ \\
\hline All categories & $-232.0(1354 \dagger)$ & $0.0(1502)$ & $-110.0(2856)$ \\
More than once a day & $-239.0(85)$ & $+75.9(189)$ & $-56.6(274)$ \\
Once a day & $-223.6(281)$ & $-0.2(501)$ & $-105.7(782)$ \\
Most days (3-6 per week) & $-210.6(176)$ & $-13.6(250)$ & $-109.1(426)$ \\
Once or twice a week & $-213.0(351)$ & $-17.9(342)$ & $-108.6(693)$ \\
Less than once a week & $-252.6(298)$ & $-6.7(165)$ & $-126.1(463)$ \\
Never & $-268.7(163)$ & $-66.2(55)$ & $-164.5(218)$ \\
$t(t$ test for linear trend) & $0.84(1332 \mathrm{df})$ & $2.04(1485 \mathrm{df})$ & $2.17(2834 \mathrm{df})$ \\
\hline
\end{tabular}

^Adjusted for lifetime cigarette consumption (set to zero for lifelong non-smokers), region of residence, and household socioeconomic group.

†Three current smokers excluded because of incomplete information on lifetime cigarette consumption. 
Table 3 Difference between observed and predicted $F E V_{l}$ by frequency of winter fruit consumption among lifelong non-smokers with no history of respiratory disease, before and after adjustment for additional environmental and lifestyle factors $\star$

\begin{tabular}{|c|c|c|c|}
\hline \multirow[b]{2}{*}{$\begin{array}{l}\text { Frequency of fresh fruit } \\
\text { consumption in winter }\end{array}$} & \multicolumn{2}{|c|}{ Observed - predicted FEV $(\mathrm{ml})$} & \multirow[b]{2}{*}{$\begin{array}{l}\text { No of } \\
\text { subjects } \dagger\end{array}$} \\
\hline & $\begin{array}{l}\text { Before adjustment } \\
(\text { model } 1)^{\star}\end{array}$ & $\begin{array}{l}\text { After adjustment } \\
(\text { model } 2)^{\star}\end{array}$ & \\
\hline $\begin{array}{l}\text { More than once a day } \\
\text { Once a day } \\
\text { Most days ( } 3-6 \text { per week) } \\
\text { Once or twice a week } \\
\text { Less than once a week } \\
\text { Never }\end{array}$ & $\begin{array}{r}+78 \cdot 9 \\
-1 \cdot 5 \\
-10 \cdot 0 \\
-20 \cdot 0 \\
-3 \cdot 9 \\
-75 \cdot 2\end{array}$ & $\begin{array}{r}+70 \cdot 3 \\
-1 \cdot 1 \\
-6 \cdot 8 \\
-22 \cdot 8 \\
+4 \cdot 1 \\
-70 \cdot 8\end{array}$ & $\begin{array}{r}185 \\
490 \\
248 \\
338 \\
165 \\
53\end{array}$ \\
\hline$t(t$ test for linear trend $)$ & $2 \cdot 08(1462 \mathrm{df})$ & $2 \cdot 10(1442 \mathrm{df})$ & \\
\hline
\end{tabular}

*Adjusted for (model 1) region of residence and household socioeconomic group; (model 2): region, socioeconomic group, urban or rural area, parental smoking, smoker in the household, alcohol consumption, effort expended at work, time spent walking daily, energetic activity in past fortnight, energetic activity in childhood.

+Both models limited to 1479 subjects with complete data on all the covariates in model 2.

FURTHER ANALYSIS AMONG HEALTHY LIFELONG NON-SMOKERS

There was evidence among the healthy lifelong non-smokers that those who consumed little fresh fruit or fruit juice tended to lead a generally less "healthy" or "health conscious" lifestyle than those consuming fruit frequently in the winter. Non-smoking subjects with a "low" fruit or juice intake were more likely than others to be living with a smoker $(41 \%$ v $32 \%$ ) or to have parents who had smoked at some time ( $88 \%$ v $84 \%$ ), but were less likely to consume alcohol regularly ( $16 \% v 19 \%)$. They were less likely to be living in a rural area $(13 \%$ $v 23 \%$ ), to have taken part in energetic leisure activities in the past fortnight $(40 \% v 54 \%)$, or to have joined with their parents in such activities as children (13\% $v 16 \%)$.

A further model (model 2 in table 3 ) was fitted for this subgroup, controlling for these indices of past and current lifestyle in addition to region and social class. This was limited to 1497 individuals with complete information on all covariates. Comparison of models 1 and 2 in table 3 shows that inclusion of these variables made little difference to the trend in $\mathrm{FEV}_{1}$ by frequency of winter fresh fruit consumption, which remained significant $(p=0.036)$. After adjustment for these additional variables the difference in mean $\mathrm{FEV}_{1}$ residual between nonsmoking subjects with "low" and "high" fruit or juice intake was $83.2 \mathrm{ml}(95 \% \mathrm{CI}-12.3$ to $178 \cdot 7 \mathrm{ml}$ ).

Although there were associations between the frequency of consumption of several other dietary items and $\mathrm{FEV}_{1}$, these were not as strong as the associations with fresh fruit in the winter and their inclusion in the analysis did not eliminate the trend in $\mathrm{FEV}_{1}$ across categories of winter fruit consumption.

\section{Discussion}

These results support the prior hypothesis of an association between infrequent fruit or fruit juice consumption and impaired ventilatory function in adults. Contrary to expectation, this was found among lifelong non-smokers as well as among current cigarette smokers. Our analysis of ventilatory function was limited to those with no history of chronic respiratory disease, which would tend towards a conservative result if low fruit intake was related to symptomatic disease. ${ }^{22}$ Similar proportions of subjects with and without such a history had low intakes of fresh fruit or fruit juice, however, suggesting that the effect of these dietary habits on symptomatic chest disease may be relatively small.

Bias in data collection is unlikely because the interview preceded assessment of ventilatory function and neither observers nor participants were aware of the hypothesis under investigation. Bias due to uncontrolled confounding remains a possibility, but the putative confounding variable would have to exert effects on lung function in lifelong non-smokers and be strongly associated with fruit consumption.

The association between fruit consumption and ventilatory function is unlikely to be due to chance. Errors in the measurement of lung function will have reduced the power of the study to detect true effects, and the crude nature of the dietary information implies that the relation between ventilatory function and specific constituents of fruit and vegetables is probably much stronger than it appears in this analysis. ${ }^{30}$ Among such specific nutrients vitamin $C$ deserves special consideration in view of the evidence presented in the introduction. Although potatoes are the main source of this vitamin for many people in Britain, ${ }^{31}$ fruit and vegetables may be more important in accounting for individual differences in vitamin C intake. ${ }^{14}$

Despite probable attenuation by imprecise dietary measurements, the variation in lung function with fresh fruit or fruit juice consumption was not trivial. The differences in adjusted $\mathrm{FEV}_{1}$ when those with "low" and "high" intakes were compared were of the order of $80 \mathrm{ml}$ and consistent across all age groups. This was about one third of the difference between current smokers and lifelong non-smokers in this population and was statistically equivalent to the decrement in $\mathrm{FEV}_{1}$ associated with smoking 20 cigarettes a day for seven years in men or 10 years in women.

Consideration of the potential role of dietary antioxidants in the pathogenesis of pulmonary emphysema ${ }^{8}$ led to the suggestion that lack of fruit and vegetables in the diet might influence the development of airflow obstruction, particularly among smokers. Our analysis, however, shows that gradients in $\mathrm{FEV}_{1}$ across categories of fruit consumption occur in younger as well as older adults, and among lifelong non-smokers as well as current cigarette smokers. Indeed, the trend in $\mathrm{FEV}_{1}$ across all categories of winter fruit intake was more consistent for the lifelong non-smokers. This suggests that other biological mechanisms may be operating to reduce ventilatory function in subjects with a low fruit intake.

Experimental studies of normal subjects have shown that vitamin $C$ supplements can attenuate the bronchoconstriction induced by ozone $^{32}$ and the increase in bronchial reactivity resulting from exposure to nitrogen dioxide. ${ }^{33}$ In another study, however, both short and long term treatment with vitamin $\mathrm{C}$ was found to 
increase bronchial reactivity in smokers. ${ }^{34}$

Possibly all or part of the observed effect of fruit consumption in adults is an indirect reflection of a relation between childhood diet and lung growth, rather than a direct dietary influence on the development of airway obstruction during adult life. This would imply that the effect of fruit consumption in childhood is even more profound, as dietary patterns are unlikely to remain fixed throughout life and the effect would be diluted in an adult population. Further observational and experimental studies of diet and respiratory disease in both adults and children are required to clarify these issues.

We are indebted to the numerous research workers who conducted the health and lifestyle survey.

1 United States Department of Health and Human Services (Public Health Service). The health consequences of smoking : chronic obstructive lung disease. A report of the Surgeon General. DHHS (PHS) 84-50205. Washington, DC United States Government Printing Office, 1984.

2 Barker DJP, Osmond C. Childhood respiratory infection and adult chronic bronchitis in England and Wales. $B M J$ 1986;293:1271-5.

3 Office of Population Censuses and Surveys. Occupational mortality. The Registrar-General's decennial supplement for Great Britain 1979-80, 1982-83. London: HMSO, 1986.

4 Fletcher CM, Peto R, Tinker C, Speizer FE. The natural history of chronic bronchitis and emphysema. Oxford: Oxford University Press, 1976.

5 Burr ML, Holliday RM. Why is chest disease so common in South Wales? Smoking, social class and lung function: a survey of elderly men in two areas. J Epidemiol Community Health 1987;41:140-4.

6 Peto R, Speizer FE, Cochrane AL, Moore F, Fletcher CM, Tinker CM, et al. The relevance in adults of air-flow obstruction, but not of mucus hypersecretion, to mortality from chronic lung disease. Results from 20 years of prospective observation. Am Rev Respir Dis 1983;128: 491-500.

7 Ebi-Kryston K. Predicting 15-year chronic bronchitis mortality in the Whitehall Study. J Epidemiol Community Health 1989;43:168-72.

8 Anderson R, Theron AJ, Ras GJ. Regulation by the antioxidants ascorbate, cysteine and dapsone of the increased extracellular and intracellular generation of reactive oxidants by activated phagocytes from cigarette smokers. Am Rev Respir Dis 1987;135:1027-32.

9 Levine $M$. New concepts in the biology and biochemistry of ascorbic acid. N Engl J Med 1986;314:892-902.

10 Carpenter $\mathrm{KJ}$. The history of scurvy and vitamin $C$. Cambridge: Cambridge University Press, 1986:199-200.

11 Calder JH, Curtis RC, Fore H. Comparison of vitamin C in plasma and leucocytes of smokers and non-smokers. Lancet 1963;i:556.

12 Brook M, Grimshaw JJ. Vitamin C concentration of plasma and leucocytes as related to smoking habit, age and sex in humans. Am J Clin Nutr 1968;21:1254-8.
13 Pelletier O. Smoking and vitamin C levels in humans. Am J Clin Nutr 1968;21:1259-67.

14 Burr ML, Elwood PC, Hole DJ, Hurley J, Hughes RE. Plasma and leucocyte ascorbic acid levels in the elderly. Am J Clin Nutr 1974;27:144-51.

15 Fulton $M$, Thompson $M$, Elton RA, Brown S, Wood DA Oliver MF. Cigarette smoking, social class and nutrient intake: relevance to coronary heart disease. Eur J Clin Nutr 1988;42:797-803.

16 Cox BD, Blaxter M, Buckle ALJ, Fenner NP, Golding JF, Gore $\mathrm{M}$, et al. The health and lifestyle survey. Preliminary report of a nationwide survey of the physical and mental health, attitudes and lifestyle of a random sample of 9003 British adults. London: Health Promotion Research Trust, 1987.

17 Fehily AM, Phillips KM, Yarnell JWG. Diet, smoking, social class and body mass index in the Caerphilly Heart Disease Study. Am J Clin Nutr 1984;40:827-33.

18 Kallner AB, Hartmann D, Hornig DH. On the requirements of ascorbic acid in man: steady-state turnover and body pool in smokers. Am J Clin Nutr 1981;34:1347-55.

19 Ministry of Agriculture, Fisheries and Food. Household food consumption and expenditure: 1984. Annual report of the National Food Survey Committee. London: HMSO 1985:48-59, 123-6.

20 Braddon FEM, Wadsworth MEJ, Davies JMC, Cripps HA Social and regional differences in food and alcohol consumption and their measurement in a national birth cohort. J Epidemiol Community Health 1988;42:341-9.

21 Lange P, Groth S, Mortensen J, Appleyard M, Nyboe J, Jensen $G$, et al. Pulmonary function is influenced by heavy alcohol consumption. Am Rev Respir Dis 1988;137 1119-23.

22 Schwartz J, Weiss ST. Dietary factors and their relation to respiratory symptoms. Am J Epidemiol 1990;132:67-76.

23 Whichelow MJ, Treasure FP. Diet and health in a random sample of British adults [abstract]. Proc Nutr Soc 1990;49:57A.

24 Office of Population Censuses and Surveys. Classification of occupations and coding index. London: HMSO, 1980.

25 Yarnell JWG, Fehily AM, Milbank JE, Sweetnam P, Walker CL. A short dietary questionnaire for use in an epidemiological survey: comparison with weighed dietary records. Hum Nutr Appl Nutr 1983;37A:103-12.

26 Chowiencyzk PJ, Lawson CP. Pocket-sized device for measuring forced expiratory volume in one second and forced vital capacity. $B M J 1982 ; 285: 15-7$.

27 Gunawardena KA, Houston K, Smith AP. Evaluation of the turbine pocket spirometer. Thorax 1987;42:689-93.

28 Schoenberg JB, Beck GJ, Bouhuys A. Growth and decay of pulmonary function in healthy blacks and whites. Respir Physiol 1978;33:367-93.

29 Miller MR, Pincock AC. Predicted values: how should we use them? Thorax 1988;43:265-7.

30 Freudenheim JL, Johnson NE, Wardrop RL. Nutrient misclassification: bias in the odds ratio and loss of power in the Mantel test for trend. Int J Epidemiol 1989:18.232-8.

31 Cade JE, Margetts BM. Nutrient sources in the English diet: quantitative data from three English towns. Int $J$ Epidemiol 1988;17:845-8.

32 Chatham MD, Eppler JH, Sauder LR, Green D, Kulle T. Evaluation of the effects of vitamin $\mathrm{C}$ on ozone-induced bronchoconstriction in normal subjects. Ann NY Acad Sci 1987; 498:269-79.

33 Mohsenin V. Effect on vitamin $\mathrm{C}$ on $\mathrm{NO}_{2}$-induced airway hyperresponsiveness in normal subjects. Am Rev Respir Dis 1987;136:1408-11.

34 Bucca C, Rolla G, Caria E, Arossa W, Bugiani M. Effects of vitamin $\mathrm{C}$ on airway responsiveness to inhaled histamine in heavy smokers. Eur Respir J 1989;2:229-33. 